Káñina, Rev. Artes y Letras, Univ. Costa Rica XXXVIII (1): 121-133, 2014 / ISSN: 2215-2636

\title{
ENCUENTROS Y DESENCUENTROS CULTURALES EN LA VÍSPERA DEL SÁBADO DE S. ROVINSKI
}

\author{
CULTURAL ENCOUNTER AND CULTURAL DIVERSITY IN \\ LA VÍSPERA DEL SÁBADO BY S. ROVINSKI**
}

Marianela Muñoz Muñoz*

"Dedico esta obra a quienes desean respirar desde sus raices y siempre se topan con segadores"

Samuel Rovinsky

\begin{abstract}
RESUMEN
El contexto histórico de la Segunda Guerra Mundial, así como las dinámicas migratorias de los primeros decenios del siglo veinte en Costa Rica se convierten en el telón de fondo de la obra La víspera del sábado de Samuel Rovinski (San José, 1980. Montréal, 1983). Dichas referencias permiten la problematización del encuentro cultural en dos dimensiones: primero, la forma como la sociedad costarricense recibe e identifica al migrante judío, los estereotipos asociados y los esfuerzos que en el seno familiar se verifican a favor de la salvaguardia de la tradición; segundo, la posibilidad de apelar a una "hermandad universal" en una época cargada de violencia, xenofobia y manipulación política, tal cual corresponde al marco temporal de la obra (diciembre de 1941 y julio de 1942).

Palabras clave: Samuel Rovinski, La víspera del sábado, encuentro cultural, historia y literatura, literatura judía, literatura costarricense, literatura de la segunda guerra mundial.
\end{abstract}

\begin{abstract}
**
The historical context of World War II and the migratory dynamics in the first decades of the XX century in Costa Rica become the background in the play La víspera del Sábado (Saturday Eve) by Samuel Rovinski (San José, 1980. Montréal, 1983). Such references allow to disturb the cultural encounter in two dimensions: in first place, the way in which the Jewish migrants are met and identified by Costa Rican society, the related stereotypes and the effort made within the family to save tradition; secondly, the opportunity to count on a "universal fellowship" in an era full of violence, xenophobia and political manipulation, which is the timeframe of the story (December 1941 and July 1942).
\end{abstract}

Key Words: Samuel Rovinski, La víspera del sábado, cultural encounter, history and literature, Jew Literature, Costa Rican literature, literature about World War II. 


\section{Introducción: una propuesta de lectura desde lo histórico y cultural}

En el capítulo IX de la Poética, Aristóteles explica la diferencia en el historiador y el poeta aclarando que esta no consiste en el uso del verso o de la prosa, sino en que "uno relata lo que ha sucedido, y el otro lo que podría suceder ${ }^{1 "}$. Gracias a esta distinción, el Estagirita afirma una cualidad más filosófica y de mayor dignidad en lo poético, en virtud del carácter universal de sus afirmaciones, frente al particular de la historia.

Nos referimos a estas nociones de la Poética sobre la poesía y no a sus teorizaciones sobre la tragedia ${ }^{2}$, porque consideramos que una de las principales virtudes de un texto-obra dramática como La víspera del sábado consiste en su posición fronteriza entre lo acaecido y lo que pudo haber sucedido. En este sentido, la referencia a lo particular (la "historia" de la familia Berlisky) conduce al lector- espectador hacia una reflexión de alcance filosófico sobre el contenido "universal" de esta "ficción": la pregunta sobre la diferencia cultural y la posibilidad del encuentro solidario a pesar de dicha diferencia.

Desde esta perspectiva, nuestra propuesta de lectura valora las relaciones entre literatura e historia, en los términos señalados por Alvarenga (2007), estableciendo puentes de convergencia, gracias a que "la historia privilegia el estudio de los sujetos, tema central del discurso literario" (2007: 30).

Igualmente, dialogamos con Zavala y Chacón, quienes en su artículo Abordaje histórico de(sde) lo literario: más allá de los límites autoimpuestos ${ }^{3}$ comprenden el texto literario como hecho histórico, documento resultante de la acción de distintas instituciones y agentes históricos y a la vez como vehículo de los discursos imperantes y de las fuerzas sociales e ideológicas actuantes en un momento dado (Zavala y Chacón, 2008).

Identificando una tradición de "límites autoimpuestos", los autores problematizan cómo la teoría de lo histórico literario ha resultado restrictiva, pues los géneros que no corresponden a la novela, más aún, a la novela histórica, suelen estar ausentes en las discusiones sobre la manifestación de lo histórico en la literatura (Ídem, p.2).

En este sentido, nuestra lectura de $L a$ víspera del sábado pretende separarse de la tendencia acusada por Zavala y Chacón. Proponemos un diálogo entre el género dramático -texto de Rovinsky- y el discurso histórico, según las investigaciones de Jacobo Schifter (Coordinador ${ }^{4}$ ), en la publicación de 1979 El judio en Costa Rica (este libro se considera un referente sobre las dinámicas migratorias de los judíos de Polonia en Costa Rica, desde los años veinte hasta la década de los sesenta del siglo pasado).

Barahona (2003) nos precede en dicha relación en sus artículos "Cuentos judíos de mi tierra: un título impostor" yen "El desdoblamiento cultural de la sociedad costarricense en un texto de Samuel Rovinski", pues Schifter representa una de las principales fuentes para su análisis sobre los contextos culturales que articulan la sociedad de los inmigrantes judíos en Costa Rica y "cómo interactúa el resto del conglomerado social con respecto a la minoría judaica" (2003b: $12^{5}$ ). Considera que en los cuentos de Rovinsky:

[hay] una preocupación manifiesta por trascender la simple anécdota o el cuadro de costumbres; el componente histórico se difumina y da paso a una reflexión exhaustiva del individuo - en este caso judío- frente a su sociedad. Se buscan cuáles son las inquietudes, las oportunidades, los prejuicios que tiene el semita en la sociedad costarricense. En síntesis, se intenta descifrar cuáles son las claves que permiten aclarar las siguientes preguntas: qué es ser judío, cuáles son las diferencias entre judíos y no judíos. (Barahona, 2003b:12).

Ahora bien, sendos artículos versan sobre el texto Cuentos judios de mi tierra (Rovinsky, 1982), con lo cual aun cuando se está alejando de las restricciones de la novela histórica, Barahona se mantiene en la línea conjuntiva entre historia y narratividad (Ricoeur, 1999) y, por lo tanto, persiste la desatención del género teatral que nos compete. 
Por su parte, en un artículo de carácter historiográfico "La dramaturgia costarricense de fin de siglo", Quesada $\left(1999^{6}\right)$ ubica La víspera del sábado en la tercera etapa de la producción de Rovinsky", en la "conflictiva década de los ochenta". Según Quesada, los textos de este periodo favorecen una reflexión sobre "las consecuencias destructoras y deshumanizantes de la intolerancia, la violencia o la represión de unos contra otros" (1999: 3); de hecho, el crítico identifica las razones culturales, junto a las políticas e ideológicas, como las motivaciones para dicha disgregación (aspecto que comulga con nuestra propuesta).

"La casa y el poder el teatro costarricense entre 1980 y 1994" de Margarita Rojas (1996) constituye el último artículo de referencia para nuestro análisis. La autora incluye la casa de los Berlosky como el protagonista mismo de $L a$ víspera de sábado. El espacio cerrado, es, en términos de Bachelard (1965), espacio nido e incluso espacio sagrado capaz de preservar a la familia de los peligros del espacio exterior y de reunirla para la celebración del Sabbat:

La casa se opone a un afuera compuesto por múltiples espacios. Por un lado, el barrio cercano de la ciudad, donde viven los más cercanos a la familia (judíos y otros inmigrantes europeos) (...) Casa, barrio, ciudad y finca lejana, se encuentran todavía dentro de una oposición más que separa Costa Rica y Europa, de donde proviene la familia inmigrante judía. Esta viaja a través de todos estos espacios, en desplazamientos que también segregan pasado, presente y futuro, por un lado, y tradición y cambio, por el otro. Desde la Europa en guerra entran a la casa las noticias a través de las ondas de radio que, sin embargo, no informan nada concreto sobre el resto de la familia dejada atrás. (Rojas, 1996: 45. El énfasis es nuestro)

Si bien Rojas valora el devenir teatral de fin de siglo (coincidente con Quesada en el proyecto historiográfico) desde la imagen de la casa, nos llama la atención la implicación histórico-cultural de este abordaje. Inicialmente, por la marca de los personajes de la obra como inmigrantes, ello en correspondencia con las dinámicas de convivencia intercultural y los efectos de las relaciones sujeto- nación -cultura que nos atañen; luego, por la referencia al acontecimiento bélico como trasfondo de los tres actos de la obra, lo cual consideramos, va más allá del tono crítico o descriptivo de la Segunda Guerra Mundial y representa en Rovinsky una esperanza: la oportunidad para pensar en "otra" historia, en "otra" respuesta humana ${ }^{8}$.

A partir de estas coordenadas teóricocríticas, analizaremos el tema del encuentro cultural en La víspera del sábado, en los siguientes apartados: primero, referiremos los procesos de acogida al migrante judío (hecho histórico), los estereotipos que ello conlleva y los esfuerzos que en el seno familiar se verifican a favor de la salvaguardia de la tradición; ello como una situación desencuentro en el encuentro.

Segundo, consideraremos el contexto de la guerra mundial y las escabrosas dinámicas de encuentro con otros grupos migrantes, específicamente con la comunidad alemana y la italiana. En el II acto de la pieza teatral, la persecución judía es remplazada "momentáneamente" por la persecución al "fascista", pero la familia logra remplazar estas actitudes de violencia promovidas por la xenofobia y los nacionalismos extremos por actitudes de verdadero encuentro cultural, en el desencuentro.

\section{El desencuentro en el encuentro cultural de La víspera del sábado}

La referencia a tres grupos culturales en La víspera del sábado resulta significativa para la comprensión de la diversidad de las identidades culturales en Costa Rica. Junto al protagonismo de la familia judía, muestra de las oleadas migratorias procedentes de Polonia desde finales de los años veinte, aparecen en el drama representantes de la colonia italiana y menciones de la alemana, cuya presencia e impacto en la construcción del Estado costarricense se documenta desde las primeras décadas del siglo XIX (Schifter, 1979; Herrera, 1981; Peters, 1980, 1992, 2002). 
Desde estas coordenadas, consideramos que es plausible una lectura del texto en su calidad de documento histórico, pero además en su dimensión testimonial y memorialista sobre las dinámicas de coexistencia -que no siempre es convivencia- multicultural de los primeros años de la década de los cuarenta.

Por un lado, el carácter histórico de la obra se posibilitaría mediante la corroboración de las actividades comerciales evocadas en la pieza teatral en los hallazgos de dicha disciplina científica, en relación con el papel de las comunidades extranjeras en el desarrollo económico nacional (Schifter, 1979; Peters, 1980, 1992).

Por otra parte, el carácter testimonial y memorialista de la obra -sin pretender decantarnos por las líneas de una crítica biografista- se propone en virtud de la identificación de los estereotipos asociados con cada grupo y principalmente aquellos provocados por las campañas anti-semitas coincidentes con el periodo de la obra, a saber, entre diciembre de 1941 (I Acto) y julio de 1942 (II y III Acto).

La simple mención de estos grupos compartiendo territorio $\mathrm{y}$ dinámicas sociales (encuentro cultural) y los desafíos para su convivencia pacífica y respetuosa (desencuentro cultural), serán analizadas a continuación.

\subsection{La actividad comercial de los judíos en Costa Rica}

Tal cual lo señala Schifter en El judio en Costa Rica (1979), la venta ambulante de telas y ropas constituye la principal actividad económica a la cual se dedican los inmigrantes poloneses a su llegada al suelo nacional ${ }^{9}$. Ello conlleva la paulatina asociación del término "buhonero" con el nombre "polaco", el cual será de uso generalizado y además connotará una serie de valoraciones peyorativas sobre el grupo y sus intereses.

Barahona refiere cómo se perciben los protagonistas de Cuentos judios de mi tierra en relación con el estigma del comerciante polaco y aduce que esta actividad económica representa a la vez, la salvación y la condena y que "esta ambigüedad conduce a un estado de angustia que no permite concretar una identidad cultural judía en suelo costarricense ni en ningún otro sueño extraño a su comunidad." (Barahona, 2003b:16).

La recurrencia de dicha angustia en $L a$ víspera de sábado llama nuestra atención, pues la pieza aborda el dilema del padre, Óscar, al atreverse a romper con dicha profesión para dedicarse -como otros judíos en una mejor situación- a la agricultura y ganadería en el ámbito rural. Por causa de su osadía, deberá enfrentar primero, el cuestionamiento de su misma familia y luego el trato hostil de la naturaleza y de las condiciones del préstamo bancario.

En el primer acto, se representa la decisión del Sr. Berlinsky de vender su clientela y comprar una finca, en consonancia inclusive con la dedicatoria del texto "Dedico esta obra a quienes desean respirar desde sus raíces y siempre se topan con segadores ..." (diálogo entre texto y paratexto). En el segundo acto, aparecen por un lado, la madre desbordada por la cantidad de costuras que requiere para colaborar en el sostenimiento de la economía familiar (otras de las actividades económicas de los judíos, véase la evolución de los comercios textiles en Schifter, 1979) y por el otro, los indicios de la enfermedad del padre.

Al finalizar, la obra y dado el carácter abierto del desenlace el lector-espectador experimentará la incertidumbre ante el fracaso o la sobrevivencia de don Óscar, por causa de una tuberculosis. Surgen preguntas en torno a un determinismo, acaso cultural: ¿quien sea de origen "polonés" podrá subsistir a únicamente como "polaco"? Al respecto, el padre debate con la madre: “¿Por qué puede ser un mal negocio una finca...? ¿De qué se han hecho las grandes fortunas en este país? ¿De vender trapos de casa en casa...? La riqueza de Costa Rica está en la agricultura... E insiste -Ester, tú sabes que no me gusta ser vendedor ambulante". (Rovinsky, 2009:245).

Sin embargo, las mismas hijas temen estar condenadas por los estereotipos asociados 
con las actividades "propias" de los judíos y se preguntan si la nueva opción, realmente los despojará de la crítica y el rechazo de los grupos mayoritarios:

REGINA: -La gente dice que nosotros los polacos sólo servimos para el comercio...

SR. B.: -Los que dicen eso son unos ignorantes antisemitas. (Sarcástico.) Como si la agricultura fuera una gran ciencia.. ¡Ya verán cuando yo trabaje esa finca! (...)

REGINA: -Cuando seamos agricultores, los antisemitas van a decir que nos estamos robando la tierra, que no somos costarricenses de "pura cepa". (Rovinsky, 2009: 250-251).

Como lectores, constatamos el esfuerzo de superación y ascenso social de la comunidad judía, mediante la diversificación de las actividades económicas $\mathrm{y}$, efectivamente, las fuentes históricas nos permiten corroborar cómo algunas figuras de este grupo se incorporaron paulatinamente a la agricultura. De hecho, Schifter incluye el discurso de Ricardo Jiménez Oreamuno al finalizar su tercer periodo presidencial en El judio en Costa Rica: "En la colonia polaca no todos son buhoneros ambulantes. Hay otras categorías: la de los empresarios y la de aquellos que se dedican a la agricultura" (En: Schifter, 1979: 195).

Este discurso resulta esclarecedor para comprender cuál es la percepción generalizada sobre los inmigrantes de Polonia y es pronunciado en defensa de las acusaciones de los oponentes del candidato, quienes reclamaban políticas represivas contra las actividades comerciales de los polacos. Schifter ilustra esta mudanza mediante el caso de don Salomón Nowalski Berman, "quien decidió después de unos cuantos meses como buhonero, dedicarse a la agricultura en la vecindad de Turrialba" (1979: 167).

Ahora bien, relevamos cómo si la decisión del cambio trasluce la esperanza del padre, la segunda generación desconfía ante la posibilidad de una auténtica integración cultural. Tal y como se mencionó, son las mismas hijas las voceras de los estereotipos padecidos y las actitudes de discriminación a las cuales son sometidas como "polacas". Introducimos, a continuación, el testimonio de las consecuencias de las campañas antisemitas en la Costa Rica de los años 40, en La víspera de sábado.

\subsection{Las campañas anti-semitas en la primera mitad del siglo $\mathrm{XX}$}

En un contexto de discriminación, donde la otredad es constituida como desigualdad, se asigna un valor negativo a las diferencias culturales (Araya y Villena, 2006) y en la obra de Rovinsky, el drama de los protagonistas radica, precisamente en el padecimiento de esa diferenciación.

Ser identificado como inmigrante judío a inicios de la década de los 40 es estar expuesto a la crítica en prensa ${ }^{10}$ y tolerar acusaciones tales como "gentes transhumantes, sin arraigo en nuestra sociedad, que van por el mundo sin buscar más norte que el de buscar la riqueza allí donde se encuentre, sin importarles un pito ni la nación, ni sus instituciones, ni el pueblo en el que viven (...)" (Schifter, 1979: 162).

Aunque históricamente no es posible afirmar que la percepción negativa haya sido generalizada, pues los testimonios recogidos por Schifter recalcan esta salvedad, en el diálogo de las hijas Berlinsky el rechazo de su ascendencia parece ser norma y ellas se interrogan si algún día dicha situación de maltrato, exclusión y desencuentro cultural finalizará:

Regina: (pensativa) Pero, ¿no crees que sería lindo vivir en una tierra donde no te discriminen, donde no te digan polaca y te hagan a un lado?

JAYA: -Por unos pocos antisemitas no debemos juzgar a todo el pueblo.

REGINA: - ¿Nos aceptarían en el Country Club o en el Club Unión? (Rovinsky, 2009: 224)

Los ámbitos de discriminación se manifiestan en la cotidianeidad, allí se reproducen prejuicios, temores y odios en contextos de interacción entre iguales. Las posibles causas de estas actitudes en relación con la comunidad judía han sido explicadas en el libro de Schifter, desde varias dimensiones, de las cuales subrayaremos dos: 
- En relación con las primeras oleadas migratorias de poloneses, se señalan las reacciones de los sectores comerciantes cuyos intereses resultan amenazados por la incursión de la figura del vendedor ambulante, el cual modifica tanto el esquema de localidad de la compra como el sistema de pago y, por ende, resulta atractivo para el consumidor. En los inicios de estas campañas y para provocar el rechazo del grupo, los buhoneros son acusados de comunistas, "propagandistas de ideas comunistas junto con sus telas baratas" (Schifter, 1979: 156).

Lo descrito se sitúa entre 1931 y 1934 y en esta primera etapa de persecución judía resulta significativo el origen económico de sus motivaciones ${ }^{11}$. Dicha situación complejiza aún más las dinámicas de encuentro cultural entre las colonias extranjeras, pues en la medida que el desarrollo del comercio se encuentra identificado con grupos específicos (españoles, italianos, libaneses, árabes, entre otros), las rivalidades en los intereses económicos empiezan a percibirse como rivalidades de origen étnico. Desde allí, la comprensión de la campaña anti- semita puede valorarse en una segunda dirección.

- Nos ubicamos en los movimientos de persecución entre 1933 a 1936 y de 1939-1941, período coincidente con la temporalización de La víspera de sábado y en consecuencia, con la II Guerra Mundial. De hecho, las noticias de la guerra y el holocausto, la imagen de los familiares ausentes, cobran los rasgos de un protagonista tácito en la obra, tal y como se observa en la siguiente cita:

SRA B.: -Cuando llegue papá nos sentamos a la mesa, porque a las seis tiene que oír las noticias de la BBC.

REGINA: - ¿Se sabe algo de Polonia?

SRA. B. . -Nada. . . ni una noticia.

REGINA - ¿Y de los abuelos y los tíos. . ., ninguna carta?
SRA. B. - ¡Cómo..., si no hay correo de Europa! Pero Dios es grande y los protegerá (...)

SR. B. (Gesto de desaliento.) -Ester, es inútil insistir... Tenemos más de un año de hacernos la misma pregunta... ¡No hay comunicación con Europa...! Los alemanes están en todo lado... ¿Qué podemos hacer? (Rovinsky, 2009: 234).

En El judio en Costa Rica se argumenta que si bien la coincidencia de un recrudecimiento en el rechazo de la colonia polaca en Costa Rica con el periodo de la II Guerra mundial no puede ser interpretada a partir de una relación de causalidad unívoca, sí es posible que la retórica y el simbolismo del nazismo hitleriano hayan sido incorporados en las posiciones anti-semitas criollas $^{12}$ (Schifter, 1979: 158).

Esta situación exacerba la tensión con la comunidad alemana e italiana, aun cuando haya representantes de estos grupos que no comulguen con el proyecto fascista. En la obra de Rovinsky se alude al desencuentro cultural derivado de esta fractura:

REGINA (Respaldando a su hermana.) -Mamá: si los alemanes llegan a Costa Rica, va a ser igual que en Polonia. ¿Quiere saber lo que me dijo Greta?; "Prepárate, polaca -me dijo- cuando llegue Hitler matará a todos los judíos"... Y lo dijo delante de mis amigas.. .

JAYA: -¿Y vos, qué hiciste? ¿No le pegaste a esa cochina" alemana?

REGINA: ¿Pegarle...? No.

JAYA: -Yo le habría dado por la boca.

REGINA: -Le di la espalda y me fui.

SRA. B. - ¡Muy bien, Regui, muy bien...! (A Jaya.) ¡No hay que pelearse...!

JAYA: - ¡Que no se atrevan a decirme una cosa de ésas porque soy capaz de hacer una barbaridad... Claro, estos alemanes se sienten muy fuertes. ¿Por qué no? ¿Acaso Costa Rica está en guerra contra ellos? (Rovinsky, 2009: 229).

El fragmento anterior ilustra los enfrentamientos entre los grupos diferenciados culturalmente y cómo la coincidencia en los espacios de socialización primaria, tales como la escuela o colegio, no estuvieron exentos de 
este tipo de choques. El fenómeno corresponde a discriminación en la interacción primaria, según Araya y Villena $\left(2006^{13}\right)$.

Ahora bien, llama la atención la ambivalencia en la posible reacción de la víctima ante su victimario: si las hijas mantienen una opinión diferenciada "defenderse o dar la espalda", en otra escena el hijo, la esperanza del futuro porque se espera llegue a ser doctor afirmará "MOISES ¡Yo no soy polaco...!, y le rompo la jeta al que me diga polaco..."; sin embargo, resulta significativo que Ester, la madre que salvaguarda la tradición rechaza la violencia e invita al perdón a pesar del desencuentro. Seguidamente, exploraremos el alcance de esta respuesta.

\section{El encuentro cultural en el desencuentro de La víspera del sábado}

Una vez identificadas las líneas dramáticas en las cuales se esboza el lamentable desencuentro acaecido en el proceso de integración cultural de la comunidad judía en general (discurso histórico) y de la familia Berlinsky, en particular (texto literario), nos detendremos en el análisis de una escena del II Acto, cuya intensificación y tono trágico sobresalen no sólo en cuanto a los efectos catárticos del temor y la compasión, sino además por la virtud de mostrar las otras persecuciones de carácter étnico cultural que se verificaron en Costa Rica, en el contexto de la II guerra Mundial (Peters y Torres, 2002).

Paradójicamente, aquel que consideramos el cuadro más violento de la obra, permite la reflexión sobre la diferencia cultural y la alteridad, con sus respectivos estereotipos, al tiempo que alecciona sobre la necesaria preponderancia del gesto solidario, cuando en derredor parecen triunfar "las consecuencias destructoras y deshumanizantes de la intolerancia, la violencia o la represión de unos contra otros" (Quesada, 1999: 3).

En relación con el contexto histórico, la escena coincide con los efectos del avance de las fuerzas antifascistas en la Segunda Guerra Mundial y la declaración de la guerra a Alemania, por parte de Costa Rica. Según Schifter, ello conllevó una especie de mudanza en la suerte de la comunidad judía cuando, a nivel de la opinión pública y de la misma institucionalidad, el foco de atención se fija en las colonias alemanas e italianas. Al respecto, el historiador añade la influencia de la campaña de Teodoro Picado, en 1943- 1944 en esta transformación y explica que "la discusión de medidas en contra de los judíos terminó, para ser remplazada por la persecución, igualmente injustificada y hasta mezquina, de la colonia alemana en Costa Rica" (Schifter, 1979: 162).

Rovinsky recrea esta situación mediante la persecución, huida y refugio del "vecino italiano" de la familia protagonista. Estos hechos se erigen en los tres ámbitos de discriminación señalados por Araya y Villena (2006, 22-24): la acción de repudio contra el "fascista" se verifica en el espacio público, es decir en el nivel de la interacción cotidiana; luego, por el contenido político e ideológico de la persecución, la víctima se pregunta si su culpa deriva tan sólo por ser italiano o se vincula con el retrato del Duce en su taller, ámbito cultural; finalmente y en correspondencia con los planteamientos de Shifter, se infiere que los motines pueden responder a las mismas disposiciones del aparato estatal, con lo cual estaría verificándose el tercer plano de la discriminación, en el sistema o estructura social.

La familia entra en contacto con las manifestaciones antifascistas en una gradatio emotiva: primero y gracias, a las noticias que lleva doña Bolcha, la vecina, se produce un debate en torno a la xenofobia y los extremos provocados por la radicalización de los nacionalismos. Se perciben las posturas diferenciadas entre la familia y este otro personaje femenino, cuya calidad moral, a pesar de pertenecer a la misma comunidad, ha sido ya puesta en entredicho desde el primer acto.

DOÑA BOLCHA -Están preparando una manifestación. Hay mucha gente allá, por el Parque Central. Quieren que se expulse a los alemanes y a los italianos. Dicen que mandan dinero a Hitler 


\begin{abstract}
y a Mussolini. ¿Qué le parece, Ester...? (Bajando la voz.) Y andan armados de palos y hierros, ¿qué le parece? (Subiendo el volumen, con satisfacción.) ¿Sabe lo que yo haría con los alemanes? Lo mismo que hicieron ellos con los judíos en el 34 : destrozarles los negocios y' las casas y meterlos en campos de concentración. ¿Que tengan de'su propia sopa...!
\end{abstract}

SRA. B. -No es buena la venganza, doña Bolcha. Aquí hay gente buena entre los alemanes...

DONA BOLCHA ¿Alemanes buenos...? Ninguno es bueno. Un alemán es un alemán. Todos son hitleristas. Si les dieran la oportunidad, nos matarían a todos. No, Ester, el mejor alemán es el alemán muerto.. .

SRA. B. - ¿Y los italianos...? Ellos no son antisemitas.

DOÑA BOLCHA - ¡Qué inocente es usted...! ¿Acaso no están unidos...? Mire, Ester, créame: hay que darles ojo por ojo y diente por diente. (Rovinsky, 2009: 263).

Al igual que en la escena referida sobre los desencuentros de las hijas Berlinsky con sus compañeras alemanas, Ester funge como intermediaria de las relaciones interculturales, apelando a la respuesta pacífica en contraste con la actitud vengativa de la vecina. Esta diferencia introducida por la voz de la madre $-\mathrm{y}$ posteriormente del padre- permite en el lector un paulatino movimiento desde lo particular, la circunstancia histórica, hacia lo universal, las respuestas del ser humano, en consonancia con el carácter "más filosófico" de la literatura.

El involucramiento de la familia con los actos de violencia y represión hacia los grupos considerados como sus anteriores "victimarios" resulta inevitable. En un primer momento, se establece una diferenciación espacial interior y exterior, pues hay una distancia entre calle, el lugar de las manifestaciones y casa, el lugar de refugio (coincidimos aquí con la visión del espacio de Margarita González (1996)), desde donde los actantes escuchan lo que pasa ex portas u observan a través de la ventana. Sin embargo, la llegada del vecino coloca a la familia ante la encrucijada de acoger o rechazar al perseguido.
Luigi acude a la casa reclamando auxilio y salvación: "¡Doña Ester..., Don Oscar..., abran, abran, por favor, Sálvenme!". Mediante las acotaciones, se observa tanto la constante del llamado como el estado del perseguido: se repite la súplica, nuevamente la súplica lastimera y los golpes en la puerta. En esta ocasión, será el padre quien decida por la familia $y$, a pesar del temor manifestado por la madre, la puerta se abre.

Desde nuestro análisis, la acción de apertura cobra un alto contenido simbólico y nuevamente filosófico sobre lo que "pudo haber sucedido" (virtud de lo poético, en términos aristotélicos) en el contexto de genocidio de la Segunda Guerra Mundial. La resolución del señor Berlinsky junto con el compromiso de la familia en torno a la protección de la víctima, posibilitan la prevalencia de actitudes de compasión y solidaridad sobre las reacciones de odio y venganza humanas; en este sentido, La víspera del sábado apela por un encuentro en medio del desencuentro (ver nota 8):

SR. B. (Desprendiéndose de su esposa.) ¡Déjame..., voy a abrir! (Sale y segundos después regresa con Luigi, el sastre: un joven de unos 25 años, flaco, bajito, de maneras tímidas.)

LUIGI (Va de uno a otro lado.) Doña Ester ..., perdóneme, doña Ester... Don Oscar, ¡Dios lo bendiga! Perdoneme, ¿pero qué podía hacer? Sólo ustedes pueden ayudarme... ¡Me van a matar... !

JAYA -No se asuste, Luigi...

LUIGI ¡Oigalos, óigalos, señorita...! Son capaces de cualquier cosa. ¿Saben lo que están haciendo...? Están destrozando todo: las cantinas, las pulperías, las tiendas, todo... Nos golpean, nos humillan en las calles. ¿Por qué a nosotros, los italianos? ¿Por qué a mí...? ¿Qué hice de malo...? Yo soy un pobre sastre. No me meto con nadie, no hago mal a nadie... Soy un trabajador...

SRA. B. -Regui..., tráigale un vaso de agua. (Regina sale.)

SRA. B. -Siéntese, Luigi..., cálmese. Aquí está a salvo... (Una piedra rompe el vidrio de la ventana. ¡"Que salga el tútile...!' Sobresalto general.'-'El grupo se aleja hacia el comedor.) (...)

LUIGI -Yo no quiero perjudicarlos, doña Ester... No quiero que vayan a sufrir por mí, pero tengo mucho miedo. 
SRA. B. -No lo vamos a entregar, Luigi..., puede estar tranquilo... (Entra Regina con el vaso de agua. Luigi lo apura a sorbos rápidos y le devuelve el vaso a Regina.)

LUIGI- ¡Muchas gracias, señorita...! (A la Sra. B.) Ustedes son muy buenas personas, ique la Virgen los bendiga! No entiendo nada de lo que pasa. Yo quiero vivir..., trabajar, doña Ester. Usted me conoce. Sabe que soy inocente. ¿Por qué, doña Ester, por qué nos persiguen...? (Rovinsky, 2009: 298. El énfasis es nuestro)

La cita anterior nos permite resaltar cómo las respuestas de amparo se manifiestan tanto en el señor y la señora Berlinsky, como en Jaya y Regina. Desde esta perspectiva y a pesar del tono trágico del texto, se trasluce una esperanza porque la nueva generación de la familia judía, la cual desea considerarse "costarricense" desde su diversidad, actúa a favor del consuelo y protección de Luigi, llamándolo incluso pariente, hermano y amigo (Rovinsky, 2009: 299).

El lector- espectador quisiera coincidir con la confianza de los señores Berlinsky: SR. B. -No se desespere,- Luigi. En cualquier momento aparece la policía y todo volverá a estar en orden... (...)SRA. B. -Ya se lo dije, Luigi... No estamos en Alemania. Esto no volverá a repetirse... (Rovinsky 2009, 299). No obstante, el reclamo de la multitud "Que salga el tútile", la angustia de muerte del perseguido y la referencia a las consecuencias de las revueltas (la destrucción de la cantina del primo del italiano) gozan de sustrato histórico:

En este marco legal, bajo fuertes presiones de los países aliados, en especial de Estados Unidos y las políticas de Defensa Hemisférica y Solidaridad Continental, la región centroamericana, y en ella Costa Rica, cuyo gobierno defendía las garantías sociales de los nacionales, proclamó la guerra contra los países del Eje y dio inicio a un periodo en la historia nacional caracterizado por las violaciones a las garantías individuales y sociales de las personas de ascendencia alemana, japonesa, italiana, e incluso costarricenses, a quienes se les acuso de ayudar o proteger a los enemigos del país por lo que fueron incluidos en las "listas negras" (Peters y Torres, 2002: 153).

Alvarenga señalaba el interés de la historia en el estudio de los sujetos y tal como "el tema central del discurso literario" (2007, 30 ); en este sentido llama la atención el eco de las consecuencias de la Segunda Guerra Mundial en Costa Rica, en el texto de Rovinsky y más que ello, cómo el telón de fondo histórico conlleva efectivamente, hacia el examen de las respuestas individuales:

LUIGI -Don Oscar..., usted sabe que yo no soy político. Nunca me meto en política...

SR. B. -Sí, lo sé, lo sé... Luigi, yo no lo estoy juzgando. Pero estamos en guerra. (...)

LUIGI -Voy a la cantina de mi primo, don Oscar..., creo que debo ayudarlo... (Dándoles la mano efusivamente.) i Don Oscar..., doña Ester! ¡ Dios los bendiga! ¡ Nunca olvidaré lo que hicieron por mí....!

SRA. B. -Sólo hicimos lo que se debe hacer por un amigo...

LUIGI -Más que a un amigo, doña Ester...jUstedes son mis hermanos!... (Y a cerca de la ventana, se asoma brevemente.) ¿No irán a volver...? (Rovinsky, 2009: 299).

En medio de los estereotipos que caracterizaron las relaciones de las diferentes comunidades culturales de la época, valoramos las acciones de la familia judía y relevamos la reacción del otro extranjero ante el gesto familiar: el agradecimiento, las bendiciones y la valoración de la auténtica amistad. Como mencionamos, el mismo Schifter explica cómo si bien muchos alemanes e italianos fueron asociados con las campañas anti-semitas, se reconoció que esta vinculación no podía generalizarse, más aún "varios comerciantes italianos - por ejemplo- mantuvieron excelentes relaciones con los judíos y cuando la suerte se volcó en contra de ellos en 1941, éstos buscarían refugio de las turbas que saqueaban sus establecimientos, precisamente en los negocios de sus amigos hebreos" (Schifter, 1979: 162. El énfasis es nuestro)

Derivado de lo anterior, proponemos que este mismo incidente refleja la capacidad del dramaturgo en recrear, en medio del clima de rechazo y persecución de los grupos, un espacio -shabatt, descanso- posible para el 
encuentro solidario entre las culturas que padecieron las consecuencias de la tragedia bélica de 1939 a 1945.

\section{A manera de conclusión: los desafíos del encuentro cultural}

Difícilmente, el drama La víspera de sábado encontrará lectores o espectadores indiferentes. Si ello ha ocurrido (está pendiente un trabajo de revisión de la crítica ante el estreno de la puesta en escena en 1984), la actitud podría ser interpretada en sí misma como una toma de postura política (Eagleton, 2002) ante la problemática social y existencial de las dinámicas de convivencia intercultural en el contexto de la Segunda Guerra Mundial en Costa Rica.

Nuestra primera conclusión, apunta la vigencia de la propuesta de la obra de Rovinsky, en relación con los desafíos de integración social, económica y cultural de las poblaciones migrantes en la sociedad costarricense. Debate del siglo XX y aún presente en la opinión y políticas públicas del siglo XXI; por ejemplo, fundamentada en un marco de derechos humanos y la normativa internacional, recientemente ha sido creada la Dirección de Integración y Desarrollo Humano en la Dirección General de Migración y Extranjería de Costa Rica ${ }^{14}$.

La identificación de lo costarricense como homogéneo y por ende excluyente aún genera discusiones desde los estudios subalternos; en ese sentido, las mismas disyuntivas enfrentadas por la familia Berlinsky en su proceso de encuentro cultural y su correspondencia con el discurso histórico, desmitifican el constructo de la nación tolerante, hospitalaria y plural que prevalece en el imaginario colectivo.

En segundo lugar y derivado de lo anterior, La víspera de sábado podría integrarse a un corpus sobre la diversidad de las identidades culturales de Costa Rica. En las mismas palabras del Sr. Berlinsky: "Todos somos costarricenses. Moishe nació en esta tierra y es tan costarricense como cualquier otro... y los hijos de ustedes también lo serán.... La gente nos dice polacos por pura ignorancia... Somos judíos costarricenses...”. El tema amerita revisión.

Coincidiríamos, entonces, con Zavala y Chacón en la comprensión del texto literario como hecho histórico cuya existencia "es resultado de la acción de distintas instituciones y agentes históricos" y cuyo contenido "muestra el impacto de los discursos imperantes y de las fuerzas sociales e ideológicas actuantes en un momento dado, y ello de manera implícita o explícita" (2008: 7).

En tercer lugar e insistiendo en el diálogo entre historia y literatura, rescatamos la contribución al proceso de lectura e interpretación del acontecimiento bélico y el genocidio de la Segunda Guerra Mundial, desde la producción literaria nacional. Las referencias al holocausto en la obra, abordadas ya por Margarita Rojas, se convierten en testimonio para la memoria histórica de un hecho que sí tuvo su incidencia en Costa Rica, no en vano La víspera del sábado inicia con una referencia visual que asocia la familia con Polonia: sobre la mesa donde la madre coloca el candelabro para el Sabbat hay "un viejo tapiz de Polonia con alguna escena bíblica, decolorado por el tiempo y raído por el trajinar de la familia".

La obra finaliza también con la referencia auditiva a la nación europea, en la radio se escuchan las noticias sobre el exterminio masivo de los judíos que provocará que los niños pierdan a sus abuelos.

Anteriormente se mencionó el carácter abierto de la obra. Se percibe la incertidumbre en cuanto al desenlace del padre y en cuanto al destino del pueblo polaco, pero no sólo en el allá, sino también en el aquí de las nuevas generaciones que enfrentarán el dilema de la venganza o el perdón, del desencuentro o del encuentro. Acaso tal encrucijada se manifiesta con más fuerza para el menor de los hijos y quizás, para el lector contemporáneo que debiera ser interpelado por la respuesta de la madre:

MOISES -¿Qué les pasa a los abuelos...?

SRA. B. -Los nazis los matarán... ¿Por qué Dios mío..., qué hemos hecho de malo? ¿Por qué nos tratas así? 
MOISES - ¿Los nazis los van a matar. . .? (Resuelto.) Yo voy a matar a los nazis... Mami, no llore. Yo voy a salvar a los abuelitos..

MOISES - ¡Pero los alemanes están matando a los abuelitos y a mucha gente...! ¿Quién los va a castigar?

SRA. B. -Dios los castigará... (La emoción le corta las palabras.)

Moishele... ¡ojalá que nunca lo obliguen a pelear! ¡No quiero verlo de soldado. .., nunca!

(La Sra. B. deja a Moisés. Va como una autómata al comedor, enciende las velas y dice la oración del shabat, como en un murmullo, sollozando. Música nostálgica. La luz se apaga lentamente.) (Rovinsky, 2009: 347. El énfasis es nuestro).

En conclusión, consideramos que el drama La víspera del sábado invita a una relectura del suceso histórico desde una postura crítica y una reflexión filosófica sobre las respuestas humanas ante la diferencia cultural, las fracturas sociales asociadas y la posible -acaso utópica- victoria de una "hermandad universal": en donde se rechaza la violencia y se enciende una vela para el descanso.

\section{Notas}

1. Utilizamos la traducción de García Yebra, Madrid Gredos, 1974

2. Si bien los sentimientos de temor y compasión asociados con el efecto de la tragedia en la Poética aristotélica se verifican en escenas de la pieza La víspera de sábado (por ejemplo, la misma persecución del italiano del Acto II), nos llama la atención cómo más allá de dichas emociones, el lector-espectador puede identificar las referencias al discurso histórico y a la vez participar de una reflexión sobre la condición humana en general y los desafíos de un encuentro cultural en contexto de migraciones y guerra, en particular.

3. Nos referimos a la ponencia presentada por Magda Zavala y Albino Chacón en el XVI Congreso internacional de literatura centroamericana, organizado por la Universidad Nacional (UNA) y la Universidad Purdue (16 al 18 de abril de 2008). El texto aparece en la respectiva Memoria electrónica http://repositorio.una.ac.cr/bitstream/ handle/11056/2654/recurso_749.pdf?sequence.

4. En la investigación participan también, los historiadores Lowell Gudmundson y Mario Solera. El libro retrata las experiencias de la comunidad judía en Costa Rica, mediante una alternancia de fuentes documentales y testimonios de representantes de la primera y segunda generación de judíos que arribó al país en la primera mitad del siglo pasado.

5. En los artículos de Barahona "Cuentos judíos de mi tierra: un título impostor" (2003a) y "El desdoblamiento cultural de la sociedad costarricense en un texto de Samuel Rovinski” (2003b) se refiere el tema de la identidad cultural y las dinámicas históricas que subyacen en Cuentos de mi tierra. No obstante, el primero decanta por un análisis de carácter estructuralista, razón por la cual se privilegia la consulta del segundo.

6. Álvaro Quesada especifica su intención historiográfica y la perspectiva de conjunto en el resumen de su ponencia "La dramaturgia costarricense de fin de siglo": "se procura ubicar la producción de los textos dramáticos, los conflictos, la temático y algunas características formales de esos textos, dentro del desarrollo de las artes escénicas y la representación teatral en Costa Rica, y dentro del contexto histórico y cultural del país" $(1999,1)$. El texto de su exposición fue publicado en la Memoria del VIII Congreso de Filología, Lingüística y Literatura Carmen Naranjo.http:// www.tec.cr/ sitios/Docencia/ciencias_lenguaje/ revista_comunicacion/VIII\%20Congreso\%20 $-20 \mathrm{Carmen} \% 20 \mathrm{Naranjo/ponencias/literatura/}$ otrosautores/pdf's/aquesada.pdf

7. La tercera etapa de la producción dramática de Rovinsky incluye, junto a La vispera del sábado, la obra Gulliver dormido (1985) y El martirio del Pastor (publicada en 1983 y estrenada en 1987). Las piezas difieren en cuanto a "estilo, factura y temática", pero Quesada subraya la crítica y el desenmascaramiento de la violencia y la deshumanización como sus puntos de encuentro.

8. Al finalizar la presentación de esta ponencia, en el VII Coloquio de Literatura Costarricense (mayo de 2013), Samuel Rovinsky compartió con el auditorio cómo al escribir la escena del italiano acogido por la familia judía, se (nos) estaba preguntando qué hubiera pasado si situaciones como estas se hubieran dado en la efervescencia de la Segunda Guerra Mundial, en el allá de Europa, valorando que quizás, otra hubiera sido la historia. Nos atrevemos 
a retomar esta reflexión post data y a la vez in memoriam del hombre que en coincidencia con la Dedicatoria de La víspera de sábado, deseó "respirar desde sus raíces".

Schifter señala la venta ambulante como una actividad practicada "casi sin excepción" por los inmigrantes poloneses en Costa Rica y explica: "si con esta empresa lograban algún éxito, la meta posterior era convertirse en propietarios de algún negocio particular. Pero aún en los casos de un rápido ascenso económico (...) los inmigrantes tuvieron que pasar varios meses o años en su condición de "buhoneros" antes de tener un local o una actividad propia" (Schifter, 1979: 149).

10. El extracto corresponde al Editorial del periódico La Tribuna (XXI n. 487317 de mayo de 1940) y la versión completa aparece completo en los anexos del libro El judío en Costa Rica.

11. Diversos estudios mantienen la hipótesis sobre el origen económico del antisemitismo. Si bien el tema excede los objetivos de este artículo, se recomienda consultar a Astro, Alan. "Pertenencia y alteridad: judíos en/de América Latina: cuarenta años de cambios." (En Shofar 31.3: 2013, 182).

12. Según Schifter, gran parte del grupo hebreo estaba consciente de que el fenómeno antisemita en Costa Rica era de carácter comercial, aunque "otros señalaron la influencia del nazismo y los alemanes en el antisemitismo costarricense". (Schifter, 1979: 331- 332).

13. Para los autores de Hacia una pedagogía del Encuentro cultural: discriminación y racismo, "la conformación de un grupo requiere unificación (integración) de aquellas personas que se consideran iguales o similares en algún sentido relevante y por contraparte, la diferenciación (separación) de quienes son percibidos como distintos". A partir de lo anterior, el espectro de las relaciones intergrupales puede movilizarse desde "relaciones de cooperación, solidaridad y respeto, hasta relaciones de indiferencia, rechazo abierto o conflictos violentos" (Villena y Jimenez, 2006: 2). Son las últimas, rechazo abierto y conflicto violento, las dinámicas que deben enfrentar los hijos de la familia Berlinsky en sus respectivos centros de estudio y las que deberán ser reemplazadas en el desenlace de la obra.

14. La Dirección General de Migración establece dentro de sus funciones "la promoción de la integración de las personas migrantes y refugiadas al seno de la sociedad costarricense". Como unidad responsable de la ejecución de una política de integración se crea la Dirección de Integración y Desarrollo Humano (DIDH) en el año 2010.

\section{Bibliografía}

Alvarenga V., Patricia. 2007. "Historia y literatura en el futuro próximo: ¿disolución de la historia en la literatura o profundización de un intercambio fructífero entre ambas?" En: Malavassi, Ana (comp). Historia: ¿ciencia, disciplina social o práctica literaria? Serie Cuadernos Teoría y metodología de la historia $\mathrm{N}^{\circ}$ 1. San José, Editorial de la Universidad de Costa Rica.

Araya J. Ma. Del Carmen y Villena F. 2006. "Hacia una pedagogía del encuentro cultural: discriminación y racismo". Serie Cuadernos para la ciudadanía $\mathrm{N}^{\mathrm{0}} 6$. Editorial Universidad de Costa Rica.

Aristóteles, Poética. 1974. (Traducción de Valentín García Yebra). España: Gredos.

Astro, Alan. 2013. "Pertenencia y alteridad: judíos en/de América Latina: cuarenta años de cambios." En: Shofar 31. 3.

Bachelard Gastón. 1965. La poética del espacio. España: Fondo de cultura económica de España S.L.

Barahona N., Alberto. 2003a. "Cuentos judíos de mi tierra: un título impostor”. En: Revista Káñina. Vol. XXVII. N. ${ }^{\circ} 1$. Universidad de Costa Rica,

.2003b. "El desdoblamiento cultural de la sociedad costarricense en un texto de Samuel Rovinski. En: Revista de Filología y Lingüistica. Vol. XXIX. Nº. 2. Universidad de Costa Rica. 
Chacón Albino. 2004. "La literatura histórica en Costa Rica hoy. Una contribución al debate teórico". En Istmo, Revista electrónica, $\mathrm{N}^{\circ} .8$.

Eagleton, Terry. 2002. Una introducción a la teoría literaria. Fondo de Cultura Económica de España.

Herrera B., Eugenio. 1985. "Los inmigrantes y el poder político en Costa Rica". En: Revista de Historia, No. 11. Universidad de Costa Rica.

Peters, Gertrud. 1992. "Café, familia y política": En: Revista de Historia $\mathrm{N}^{\circ} .25$. Universidad de Costa Rica, Universidad Nacional.

.1980. "La formación territorial de las grandes fincas de café en la Meseta Central: estudio de la firma Tournon: 1877-1955". En: Revista de Historia No. 9-10. Universidad de Costa Rica.

Peters, Gertrus y Torres. 2002. "Las disposiciones legales del gobierno costarricense sobre los bienes de los alemanes durante la segunda guerra mundial". Anuario de Estudios Centroamericanos, Vol. 28, No. 1/2. Universidad de Costa Rica.

Quesada, Alvaro. "La dramaturgia costarricense de fin de siglo" En: Revista de Comunicación ITCR. Versión digital consultada el 3 de mayo de 2011. En: http://www.tec.cr/ sitios/docencia/ ciencias_lenguaje/revista_comunicacion/ viii $\% 20$ congreso $\% 20-20$ carmen $\% 20$ naranjo/ponencias/literatura/otrosautores/ pdf's/aquesada.pdf

Ricoeur, Paul. 1999. Historia y Narratividad. Editorial Paidós. Barcelona, España.

Rojas G., Margarita. 1996. "La casa y el poder. El teatro costarricense entre 1980 y 1994". En: Espejo de paciencia (2).

Rovinsky, Samuel. 2009. Gobierno de Alcoba Un modelo para Rosaura - La víspera del sábado. Editorial Costa Rica (Colección autores costarricense del S.XX).

1997. Cuentos judios de mi tierra. Editorial Costa Rica.

Schifter et al. 1979. El judio en Costa Rica. Editorial UNED, Costa Rica.

Zavala, Magda y Chacón A. “Abordaje histórico de(sde) lo literario: más allá de los límites autoimpuestos". En: Memoria electrónica del XVI Congreso internacional de literatura centroamericana. Recuperado el 30 de marzo de 2013. http://repositorio. una.ac.cr/bitstream/handle/11056/2654/ recurso_749.pdf?sequence.

\section{(@) $\mathbb{\otimes \Theta}$}

Este obra está bajo una licencia de Creative Commons Reconocimiento-NoComercial-SinObraDerivada 4.0 Internacional. 
